\title{
Deciphering the signaling networks underlying simvastatin-induced apoptosis in human cancer cells: evidence for non-canonical activation of RhoA and Rac1 GTPases
}

\author{
Y Zhu ${ }^{1,2}$, PJ Casey ${ }^{3,4}$, AP Kumar ${ }^{5,6,7,8}$ and S Pervaiz ${ }^{\star, 1,2,4,6,8,9}$
}

\begin{abstract}
Although statins are known to inhibit proliferation and induce death in a number of cancer cell types, the mechanisms through which downregulation of the mevalonate (MVA) pathway activates death signaling remain poorly understood. Here we set out to unravel the signaling networks downstream of the MVA pathway that mediate the death-inducing activity of simvastatin. Consistent with previous reports, exogenously added geranylgeranylpyrophosphate, but not farnesylpyrophosphate, prevented simvastatin's growth-inhibitory effect, thereby suggesting the involvement of geranylgeranylated proteins such as Rho GTPases in the anticancer activity of simvastatin. Indeed, simvastatin treatment led to increased levels of unprenylated Ras homolog gene family, member A (RhoA), Ras-related C3 botulinum toxin substrate 1 (Rac1) and cell division cycle 42 (Cdc42). Intriguingly, instead of inhibiting the functions of Rho GTPases as was expected with loss of prenylation, simvastatin caused a paradoxical increase in the GTP-bound forms of RhoA, Rac1 and Cdc42. Furthermore, simvastatin disrupted the binding of Rho GTPases with the cytosolic inhibitor Rho GDl $\alpha$, which provides a potential mechanism for GTP loading of the cytosolic Rho GTPases. We also show that the unprenylated RhoA- and Rac1-GTP retained at least part of their functional activities, as evidenced by the increase in intracellular superoxide production and JNK activation in response to simvastatin. Notably, blocking superoxide production attenuated JNK activation as well as cell death induced by simvastatin. Finally, we provide evidence for the involvement of the B-cell lymphoma protein 2 family, Bcl-2-interacting mediator (Bim), in a JNK-dependent manner, in the apoptosis-inducing activity of simvastatin. Taken together, our data highlight the critical role of non-canonical regulation of Rho GTPases and involvement of downstream superoxide-mediated activation of JNK pathway in the anticancer activity of simvastatin, which would have potential clinical implications.
\end{abstract}

Cell Death and Disease (2013) 4, e568; doi:10.1038/cddis.2013.103; published online 4 April 2013

Subject Category: Cancer

Statins are 3-hydroxy-3-methyl-glutaryl-CoA (HMG-CoA) reductase inhibitors that have been widely used as cholesterol-lowering agents to treat hyperlipidemia in the clinic. In the last decade, mounting experimental evidence has demonstrated that statins exert cytostatic and pro-apoptotic effects in a wide variety of cancers, including breast carcinoma, prostate carcinoma, colorectal carcinoma, lung carcinoma, glioblastoma, osteosarcoma, acute myeloid leukemia (AML), multiple myeloma and skin carcinoma. ${ }^{1-7}$ Statins inhibit cell proliferation by arresting cancer cells in the $\mathrm{G} 1$ or $\mathrm{S}$, and occasionally $\mathrm{G} 2 / \mathrm{M}$, phase by modulating cell cycle regulatory proteins. ${ }^{8,9}$ For example, statins were shown to regulate $\mathrm{G} 1 / \mathrm{S}$ arrest in colorectal cancer cells by upregulating p21 and p27 expression and downregulating cyclin-dependent kinase 2 activity. ${ }^{7}$

In addition to their effects on cell proliferation, statins have also been reported to induce apoptosis in cancer cells. Although there is experimental evidence to implicate protein geranylgeranylation in the regulation of statin-mediated apoptosis, a complete understanding of the functional

\footnotetext{
${ }^{1}$ Department of Physiology, Yong Loo Lin School of Medicine, National University of Singapore, Singapore; ${ }^{2}$ NUS Graduate School for Integrative Sciences and Engineering, Singapore; ${ }^{3}$ Department of Pharmacology and Cancer Biology, Duke University Medical Center, Durham, NC, USA; ${ }^{4}$ Cancer and Stem Cell Biology Program, Duke-NUS Graduate Medical School, Singapore; ${ }^{5}$ Department of Pharmacology, Yong Loo Lin School of Medicine, Singapore; ${ }^{6}$ Cancer Science Institute of Singapore, Yong Loo Lin School of Medicine, Singapore; ${ }^{7}$ School of Biomedical Sciences, Faculty of Health Sciences, Curtin University, Perth, WA, Australia; ${ }^{8}$ Department of Biological Sciences, University of North Texas, Denton, TX, USA and ${ }^{9}$ Singapore-MIT Alliance, Singapore

*Corresponding author: S Pervaiz, Department of Physiology, Yong Loo Lin School of Medicine, National University of Singapore, 2 Medical Drive, Building MD9 \#02-04, Singapore 117597, Singapore. Tel: +65 6516 6602; Fax: +67 788 161; E-mail: phssp@nus.edu.sg

Keywords: apoptosis; JNK; Rho; simvastatin; superoxide

Abbreviations: ActD, actinomycin D; AML, acute myeloid leukemia; Bax, Bcl-2-associated X protein; Bcl-2, B-cell lymphoma protein 2; Bim, Bcl-2-interacting mediator; Bim-EL, Bim-extra long; Caspase, cysteine-dependent aspartate-specific protease; Cdc42, cell division cycle 42; CHX, cycloheximide; DHE, dihydroethidium; DPI, diphenyleneiodonium; ERK, extracellular-regulated kinase; FPP, farnesyl pyrophosphate; FTI, farnesyltransferase inhibitor; GGPP, geranylgeranylpyrophosphate; GGTI, geranylgeranyltransferase inhibitor; HMG-CoA, 3-hydroxy-3-methyl-glutaryl-CoA; MEK, meiosis-specific serine/threonine protein kinase; MTT, 3-(4,5dimethylthiazol-2-yl)-2,5 diphenyltetrazolium bromide; MVA, mevalonate; NOX, NADPH oxidase; PARP, poly (ADP-ribose) polymerase; Rac, Ras-related C3 botulinum toxin substrate; Ras, rat sarcoma; RhoA, Ras homolog gene family, member A; RhoGDI, Rho GDP-dissociation inhibitor; zVAD-fmk, benzyoxycarbonyl valanyl alanylfluoromethylketone
}

Received 28.1.13; revised 23.2.13; accepted 25.2.13; Edited by A Stephanou 
mechanisms underlying the death-inducing effect of statins in cancer cells is lacking. Recent advances in this regard provide evidence to implicate the mitogen-activated protein kinase pathway in the anticancer activity of statins. To that end, lovastatin was shown to induce apoptosis in AML cells by downregulating the pro-survival Raf-MEK-ERK pathway. ${ }^{10}$ In a separate study, statin-induced apoptosis in osteosarcoma cells was shown to be mediated by the inhibition of extracellular-regulated kinase (ERK) signaling and downregulation of $\mathrm{B}$-cell lymphoma protein 2 (Bcl-2) expression, downstream of Ras homolog gene family, member A (RhoA) inhibition. ${ }^{5}$ Other reports have also suggested that statins mediate apoptotic response by activating Fas (cluster of differentiation 95-Apo1)-induced apoptotic signaling via their ability to disrupt cholesterol-enriched lipid rafts. ${ }^{11}$ More importantly, the cytostatic and cytotoxic effects of statins are significantly more pronounced in malignant cells compared with non-malignant cells, which has been attributed to the higher expression of HMG-CoA reductase and a greater need for mevalonate (MVA)-derived isoprenoids in cancer cells. ${ }^{12}$ Therefore, statins are promising treatment options, with a high therapeutic index and demonstrated specificity in targeting cancer cells. ${ }^{13,14}$ However, epidemiological studies and clinical trials assessing the clinical efficacy of statins for treating cancers have drawn controversial conclusions. ${ }^{15,16}$ Hence, a better understanding of the mechanisms underlying the anticancer activity of statins is desirable to identify specific targets and signaling networks for potential therapeutic relevance.

Here, we set out to investigate the molecular mechanisms underlying the apoptotic activity of statins in human colorectal carcinoma cells, particularly focusing on the MVA-regulating activity of statins. Our results provide evidence that simvastatin-induced apoptosis is mediated by GTP loading of unprenylated Rho GTPases, and involves the intermediacy of JNK-mediated Bcl-2-interacting mediator (Bim) activation, downstream of intracellular superoxide production. These data provide a novel underlying mechanism for the anticancer activity of simvastatin, which could have potential implications for the strategic use of statins in the management of cancer.

\section{Results}

Simvastatin activates mitochondrial-mediated death pathway by inhibiting protein geranylgeranylation in HCT116 cells. In the present study, we first examined the effects of simvastatin on the viability of HCT116 colorectal cancer cells. Simvastatin induced potent cell loss in a dosedependent manner (Figure 1a) and impaired the ability of cancer cells to form colonies in a longer-term assay (Figure 1b). We then determined the ability of MVA and two of its downstream metabolites to rescue the statininduced decrease in cancer cell viability. Simvastatininduced cytotoxicity and colony-inhibition effects were completely prevented by preincubation with MVA and largely so by geranylgeranylpyrophosphate (GGPP), whereas farnesylpyrophosphate (FPP) was much less effective (Figures 1a and b). Moreover, the protein geranylgeranyltransferase I (GGTase-I) inhibitor geranylgeranyltransferase inhibitor (GGTI)-298, but not the protein farnesyltransferase inhibitor (FTI)-277, induced cell loss (Supplementary Figure S1A), supporting a more important role of protein geranylgeranylation than farnesylation in simvastatin's cytotoxic effects. Assessment of proteolytic cleavage of cysteine-dependent aspartate-specific protease (caspase)-3 as well as cleavage of the caspase- 3 substrate poly (ADPribose) polymerase (PARP) confirmed that simvastatininduced cell death in HCT116 cells was consistent with apoptotic execution, which could be prevented by the pan-caspase inhibitor benzyoxycarbonyl valanyl alanylfluoromethylketone (zVAD-fmk) as well as preincubation with MVA or GGPP (Figures 1c and d). Our results also implicate the mitochondrial death amplification pathway in simvastatin-induced apoptosis, as evidenced by mitochondrial translocation of $\mathrm{Bcl}-2$-associated $\mathrm{X}$ protein (Bax) and the cytosolic release of cytochrome $c$ required for efficient apoptosome assembly (Figure 1e). The involvement of Bax was further corroborated by data, demonstrating that HCT116 Bax-deficient cells were relatively resistant to the apoptosis-inducing effect of simvastatin (Figure $1 \mathrm{f}$ and Supplementary Figure S2). These data indicate that simvastatin induces apoptosis via caspase- and Bax-dependent mechanisms.

Increased GTP loading of newly synthesized RhoA and Rac1 is responsible for simvastatin-induced cell death. In order to identify the downstream targets of protein geranylgeranylation affected by simvastatin treatment in HCT116 cells, we focused on looking at three well-studied geranylgeranlyated proteins: RhoA, Ras-related C3 botulinum toxin substrate (Rac)1 and cell division cycle 42 (Cdc42). We first assessed the activation status of these Rho proteins after simvastatin treatment. Interestingly, using a GST-protein-binding domain pull-down assay, we show that simvastatin treatment resulted in a significant increase in GTP-loaded RhoA, Rac1 and Cdc42, and also concomitant increases in the protein levels of RhoA and Cdc42 (Figure 2a). This increment in protein expression and GTP loading was significantly blocked by GGPP preincubation, but less so by FPP (Figure 2b). We then tested the hypothesis that the activation of these Rho-family proteins was involved in the apoptotic effects of simvastatin. Indeed, pharmacological inhibitors of Rac1 (NSC23766 and EHT1864) or expression of the dominant-negative Rac1N17 significantly protected cells from simvastatin-induced apoptosis (Figure 2c). In addition, transfection of siRNAs targeting RhoA or Rac1, but not Cdc42, partially abrogated simvastatin-induced apoptosis (Figure 2d), suggesting the importance of RhoA and Rac1 activation in simvastatin-induced cell death. To further characterize the impact of simvastatin treatment on RhoA, Rac1 and Cdc42, we assessed the prenylation and localization status of these proteins. To quantify Rho prenylation, we extracted cells in the low cloudpoint detergent Triton $\mathrm{X}-114,{ }^{17}$ which separates cell lysates into an aqueous and detergent phase based on the hydrophobicity of the respective proteins. Previous work has shown that unprenylated rat sarcoma (Ras) and Rhofamily proteins partition into the aqueous phase, whereas prenylated proteins partition into the detergent phase. ${ }^{18,19}$ We observed an increase of all three Rho proteins in the 
a

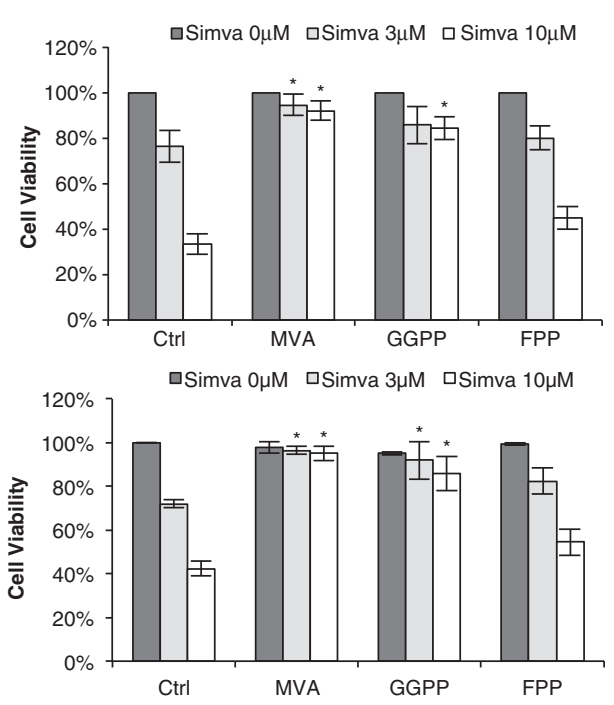

C

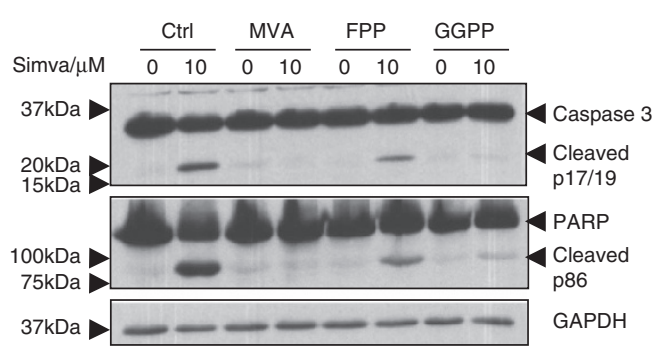

e

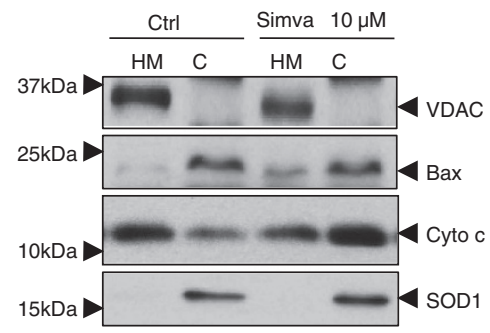

b

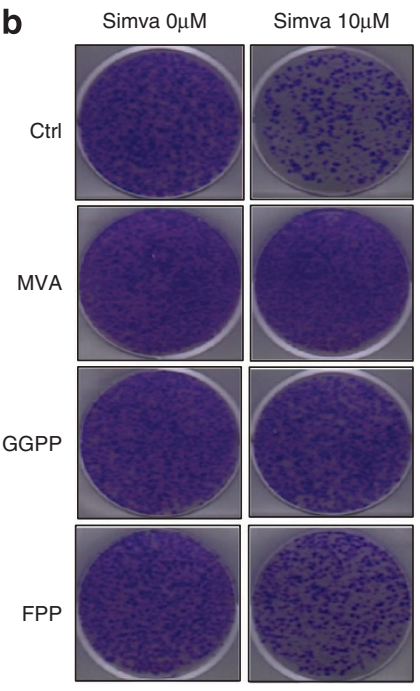

d

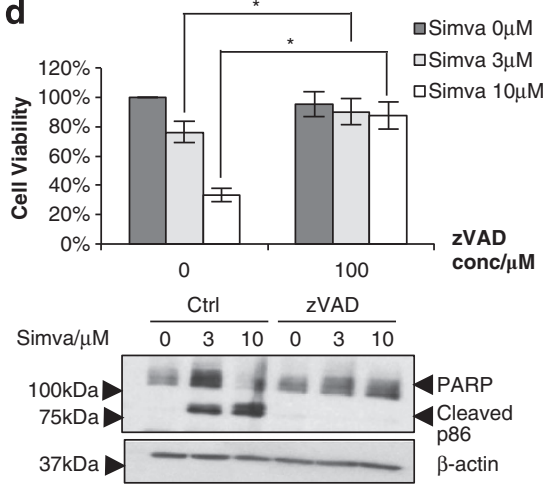

$\mathbf{f}$
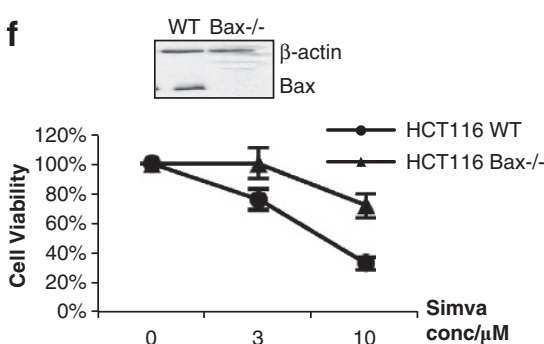

Figure 1 Simvastatin activates mitochondria-mediated death pathway by inhibiting protein geranylgeranylation in HCT116 cells. (a) Cells were preincubated with or without $100 \mu \mathrm{M}$ MVA, $10 \mu \mathrm{M}$ GGPP or $10 \mu \mathrm{M}$ FPP for $1 \mathrm{~h}$ before treatment with simvastatin for $48 \mathrm{~h}$. Cell viability was assessed by crystal violet staining (upper panel) and MTT assay (lower panel). (b) Following the previous treatment, 10000 cells were seeded onto 6-well plates for assessment of colony formation. (c) Cleavage of caspase-3 and PARP was measured after $36 \mathrm{~h}$ of simvastatin treatment and assessed by western blotting. (d) Cells were preincubated with $100 \mu \mathrm{M}$ zVAD-fmk for $1 \mathrm{~h}$ before exposure to simvastatin, cell viability was assessed by crystal violet staining and cell lysates were probed for PARP cleavage. (e) After $24 \mathrm{~h}$ of simvastatin treatment, subcellular fractions of mitochondria-enriched heavy membranes (HM) and cytosol (C) were prepared and subjected to western blotting. (f) Cell viability of HCT116 WT and Bax ${ }^{-1-}$ cells upon simvastatin treatment was assessed by crystal violet staining. Data are shown as mean \pm S.D. of at least three independent experiments. ${ }^{*} P<0.05$ compared with simvastatin treatment alone. And all immunoblots are representative of at least two independent experiments

aqueous phase, which corresponded to the level of unprenylated proteins (Figure 2e). Next, we studied the localization of these Rho proteins after simvastatin treatment, with focus on two cellular locations: the lipid rafts and the cytosol. The lipid rafts are microdomains within the plasma membrane that are enriched with sphingolipids and cholesterol. ${ }^{20-22}$ Lipid rafts can be isolated by the virtue of their detergent insolubility and characterized by the presence of bona fide raft-associated proteins, such as flotillin after ultracentrifugation in a sucrose gradient density. ${ }^{23}$ Studies have shown that Rho GTPases are found to be associated with the lipid rafts of the plasma membrane. ${ }^{24}$ Further analysis revealed that these Rho proteins were decreased from the detergent-resistant membrane (DRM, also referred to as lipids raft) component of the plasma membrane (Figure 2f) and increased in the cytosolic fraction (Figure 2g) upon simvastatin treatment. Together, these data provide evidence to implicate cytosolic, yet activated, 
a
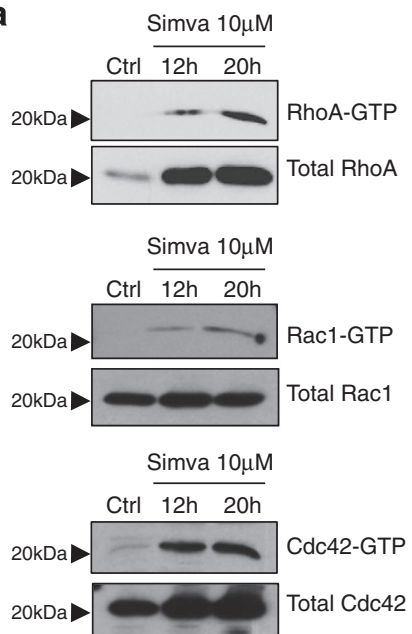

b MVA GGPP FPP

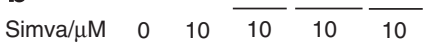

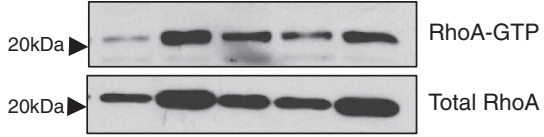

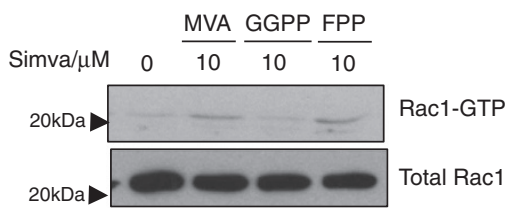

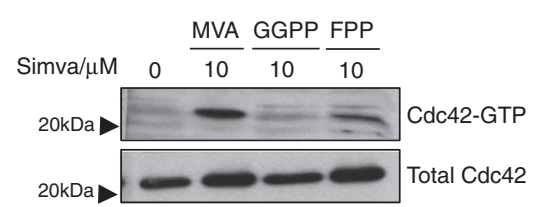

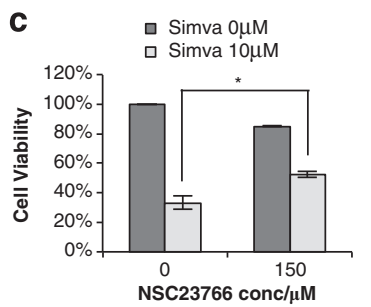
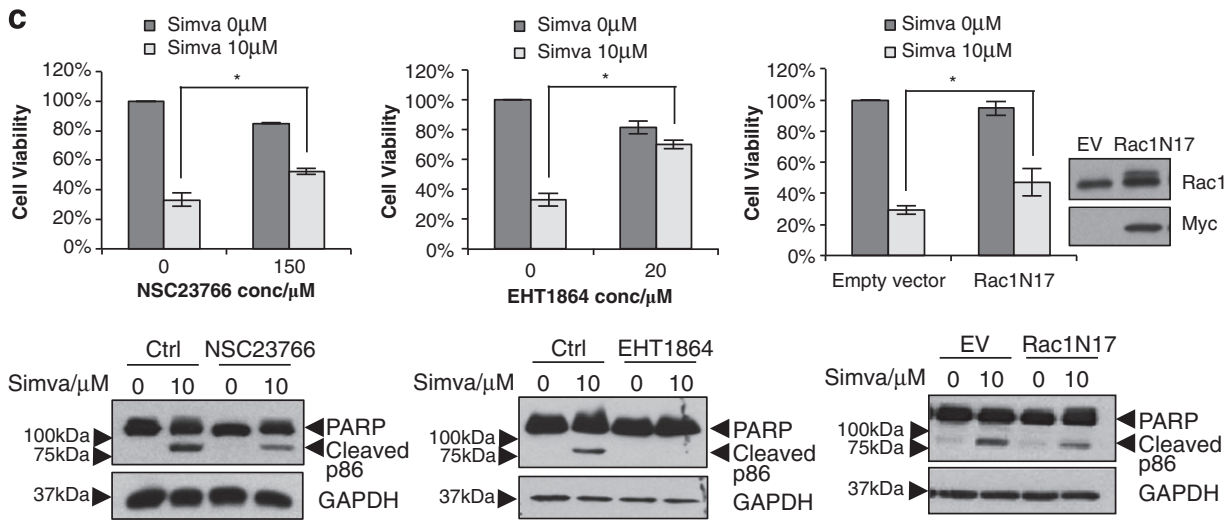

d
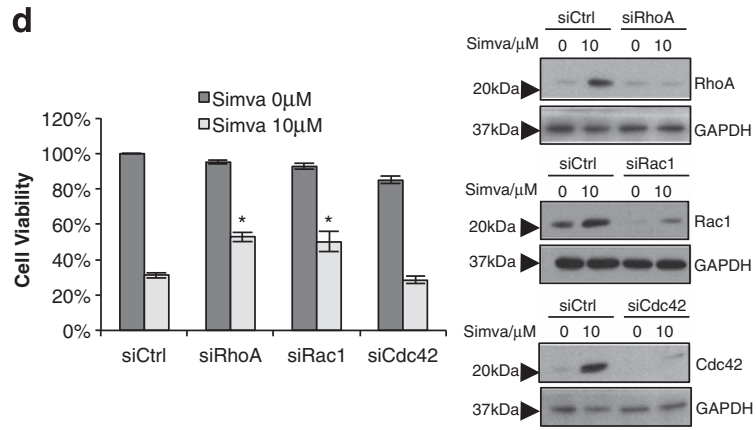

e Aqueous Detergent

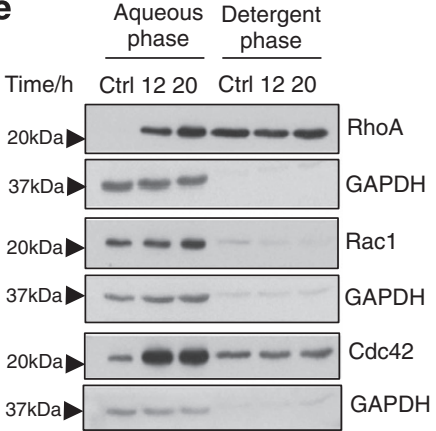

f

Simva $10 \mu \mathrm{M}$

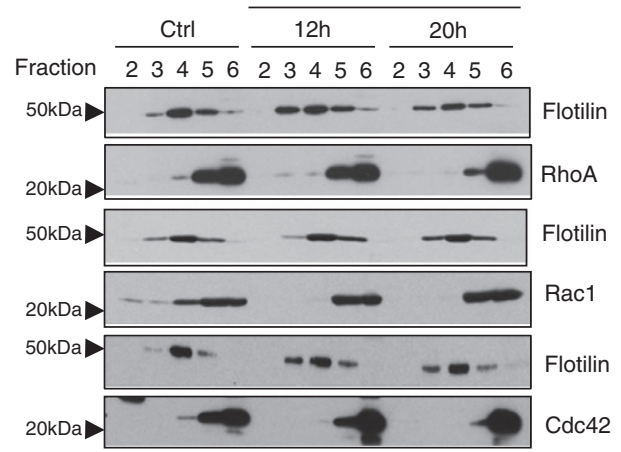

g Simva $10 \mu \mathrm{M}$ Cytosol Ctrl $12 \mathrm{~h} 20 \mathrm{~h}$ $20 \mathrm{kDa}-\mathrm{RhoA}$ $15 \mathrm{kDa}=\mathrm{SOD} 1$ $20 \mathrm{kDa}-2$ Rac1 $15 \mathrm{kDa}-\infty$ SOD1 $20 \mathrm{kDa}-\mathrm{Cdc} 42$ $15 \mathrm{kDa}-\infty-$ SOD1 
RhoA and Rac1 in death signaling induced upon exposure of cancer cells to simvastatin.

To understand the non-canonical increase of GTP-bound RhoA and Rac1 in the wake of simvastatin treatment, we looked at the interaction of Rho proteins with their cytosolic sequestrant Rho GDP-dissociation inhibitor (RhoGDI) $\alpha$, as earlier findings have indicated that unprenylated Rho proteins can no longer interact with RhoGDIs. ${ }^{25}$ Indeed, we found that simvastatin treatment significantly impaired the association of RhoA and Rac1 with RhoGDl $\alpha$ (Figure 3a), suggesting a mechanism for enhanced GTP loading of these GTPases.

As protein prenylation is a post-translational modification, inhibition of protein synthesis would be expected to prevent simvastatin-dependent apoptosis. To test this hypothesis, we assessed the effect of protein synthesis inhibitor cycloheximide on simvastatin-treated HCT116 cells. Indeed, cells pretreated with cycloheximide were rendered insensitive to simvastatin, as shown by a significant decrease in simvastatin-induced PARP cleavage (Figure $3 \mathrm{~b}$ ), confirming that simvastatin-mediated apoptosis is dependent on the presence of newly translated proteins. Furthermore, we showed that cycloheximide pretreatment completely prevented simvastatin-induced accumulation of RhoA- and Rac1-GTP, while it alone had little effects on their activation status (Figure 3c).

Simvastatin induces intracellular superoxide production downstream of RhoA and Rac1 activation. The critical role of RhoA and Rac1 activation in mediating the antitumor effects of simvastatin prompted us to investigate the downstream effectors of RhoA and Rac1 involved in transmitting the signal. One such candidate effector molecule is the
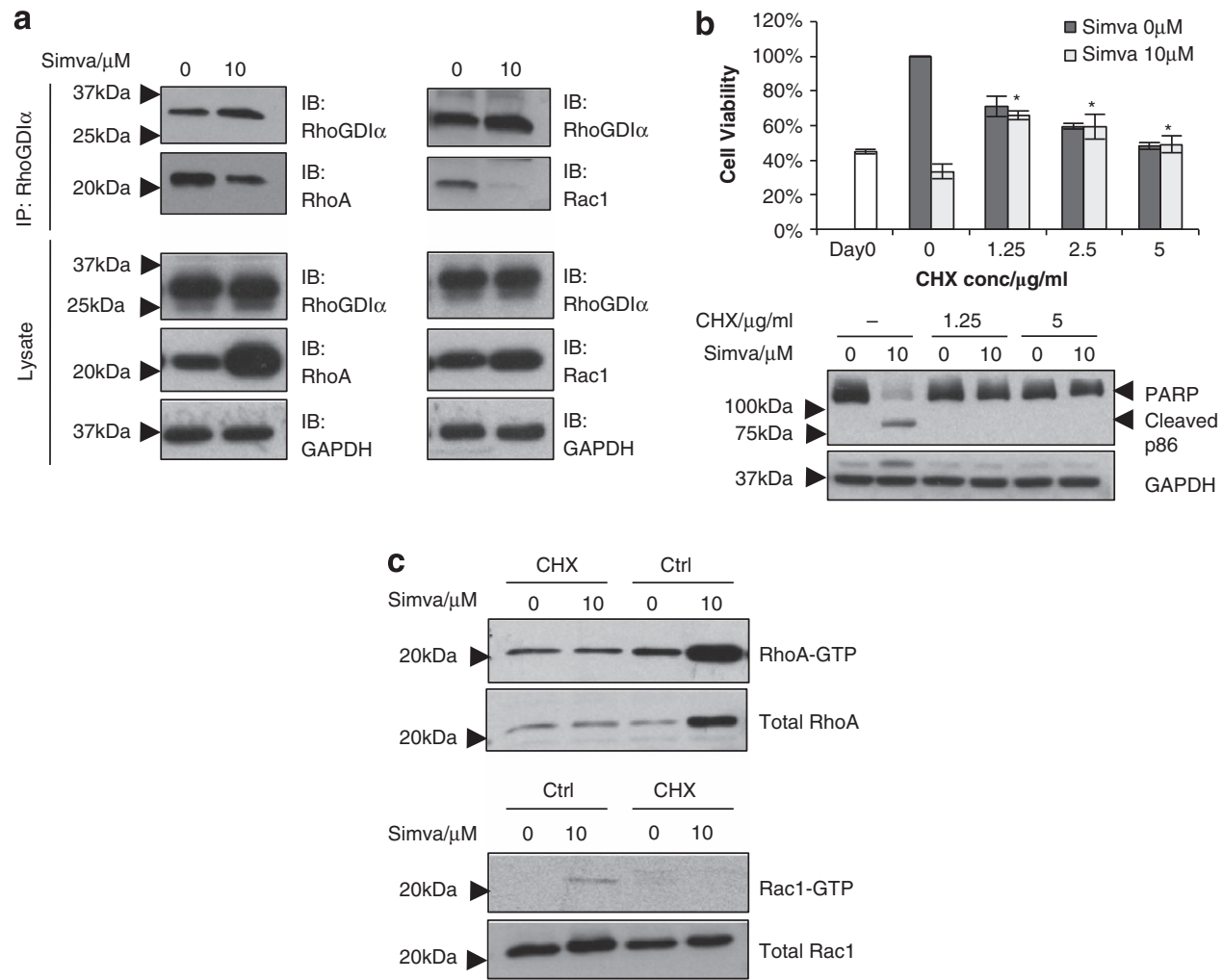

Figure 3 Newly synthesized RhoA and Rac1 are not sequestered by RhoGDl $\alpha$ and allows for GTP loading. (a) Cells were treated with simvastatin for $20 \mathrm{~h}$ and RhoGDI $\alpha$ was immunoprecipitated from cell lysates. Immunoprecipitated proteins were then assessed by western blotting. (b) Cells were preincubated with various concentrations of $\mathrm{CHX}$ before simvastatin treatment. Cell viability was assessed by crystal violet staining and the lysates were probed for PARP cleavage. Data are shown as mean \pm S.D. of at least three independent experiments. ${ }^{*} P<0.05$ compared with simvastatin treatment alone. (c) Cells were preincubated with $5 \mu \mathrm{g} / \mathrm{ml} \mathrm{CHX}$ before simvastatin treatment for $20 \mathrm{~h}$, and RhoA and Rac1 GTP loading was assessed. All immunoblots are representative of at least two independent experiments

Figure 2 Increased GTP loading of RhoA and Rac1 is responsible for simvastatin-induced cell death. (a) Cells were treated with simvastatin for the indicated duration; (b) cells were preincubated with MVA, GGPP or FPP. In Both (a) and (b), GTP-bound RhoA, Rac1 and Cdc42, together with total cell lysates were assessed by western blotting. (c) Cells were subjected to preincubation with $150 \mu \mathrm{M}$ NSC23766, $20 \mu \mathrm{M}$ EHT1864 or expression of dominant-negative mutant Rac1N17 before simvastatin treatment. Cell viability was assessed by crystal violet staining, and cell lysates were probed for PARP cleavage. Rac1 and Myc expression was also assessed to confirm the successful transfection of Rac1N17 plasmid. Data are shown as mean \pm S.D. of at least three independent experiments. ${ }^{*} P<0.05$ compared with simvastatin treatment alone. (d) Cells were silenced with RhoA, Rac1 or Cdc42 before treatment with simvastatin, and cell viability was assessed by crystal violet staining. In (e-g), cells were treated with simvastatin for 12 and $20 \mathrm{~h}$. (e) Cell lysates were separated into aqueous and detergent-rich phases using Triton X-114 phase-separation assay. (f) Lipid raft fractions were prepared using sucrose gradient ultracentrifugation. $(\mathbf{g})$ The cytosolic fractions of cells free from contaminations from membranes were obtained from ultracentrifugation. Following the preparation procedures in $(\mathbf{e}-\mathbf{g})$, protein expression of RhoA, Rac1 and Cdc42 was assessed by western blotting. All immunoblots are representative of at least two independent experiments 
reactive oxygen species superoxide, as both RhoA and Rac1 have been shown to be involved in intracellular superoxide production. ${ }^{26,27}$ In HCT116 cells, simvastatin triggered sustained superoxide production as measured by two independent methods, lucigenin chemiluminescence assay (Figure 4a) and the superoxide-sensitive fluorescent dye dihydroethidium (DHE; Figure 4b). Preincubation with three different types of cell permeable superoxide scavengers, namely diphenyleneiodonium (DPI), Tempol and Tiron, significantly abrogated simvastatin-induced caspase-3 cleavage and cell loss (Figure 4c), confirming that superoxide is an important signaling molecule in the apoptotic execution. To further understand the link between superoxide production and activation of Rho GTPases, we measured intracellular superoxide levels after preincubation with MVA, GGPP or FPP and in response to inhibition of RhoA, Rac1 and Cdc42 activities. In agreement with the cell viability data, MVA or GGPP preincubation completely blocked simvastatin-induced superoxide production (Figure 4d). In addition, treatment with Rac1 inhibitor and Rac1N17 as well as siRNAs against RhoA or Rac1 also significantly lowered simvastatin-induced superoxide production (Figure 4e). These findings suggest that superoxide production is a downstream effector of RhoA and Rac1 activation, following simvastatin treatment.

Simvastatin induces JNK activation downstream of Rho GTPases and superoxide production. Signaling by Rho GTPases or oxidative stress is known to activate the JNK pathway. ${ }^{28,29}$ Consistent with these observations, we also observed sustained JNK activation as shown by the phosphorylation at Thr183 and Tyr185 following simvastatin treatment (Figure 5a). Additionally, pharmacological inhibitor of JNK kinase, SP600125, significantly blocked the cytotoxic effects of simvastatin (Figure 5b), confirming the essential role of JNK in apoptosis induction. We next asked whether a a

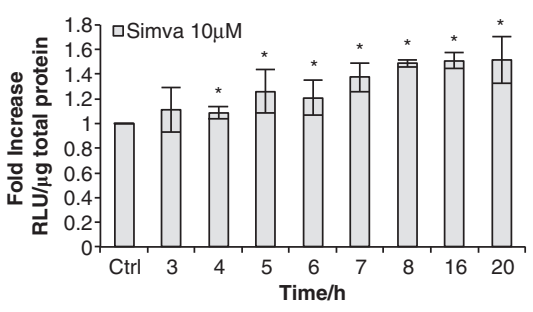

b $\quad$ SSimva $10 \mu \mathrm{M}$
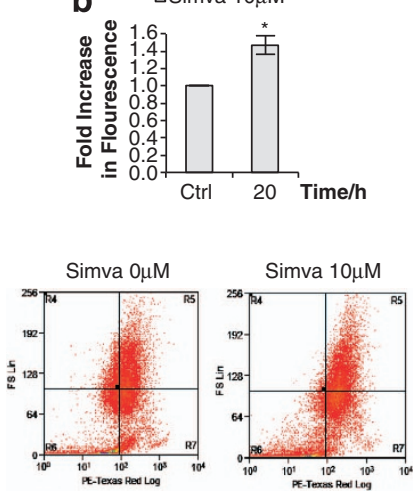

C
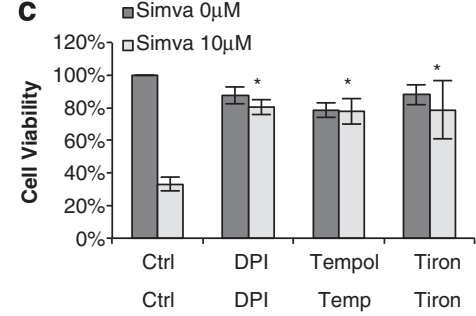

$\begin{array}{llllllllllllllllllll}\text { Simva } / \mu M & 0 & 3 & 10 & 0 & 3 & 10 & 0 & 3 & 10 & 0 & 3 & 10\end{array}$

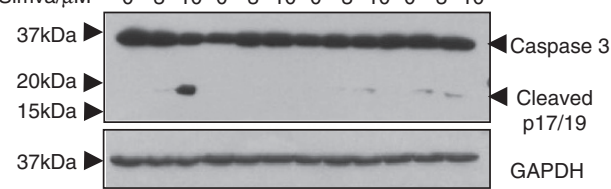

d

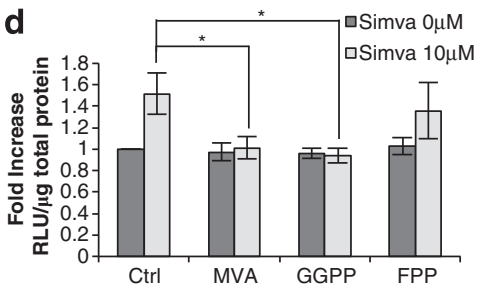

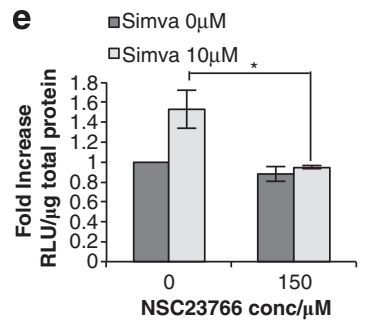
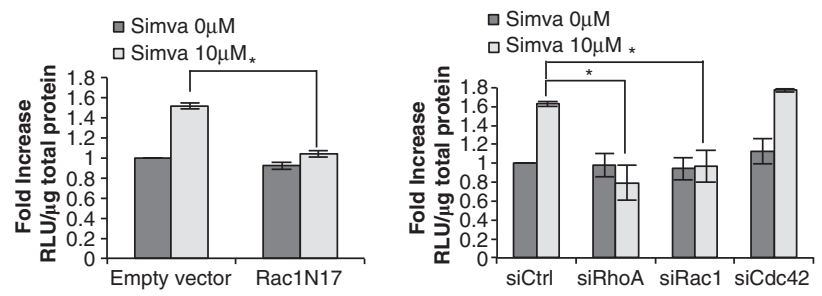

Figure 4 Simvastatin induces intracellular superoxide production downstream of RhoA and Rac1 activation. Cells were treated with simvastatin for the indicated time points. The intracellular superoxide level was determined using (a) a lucigenin-based chemiluminescence assay and (b) a fluorescent dye DHE. Density plots after $20 \mathrm{~h}$ of simvastatin treatment were displayed as cell size (FS Lin) against DHE fluorescence (PE-Texas Red). Data are shown as mean \pm S.D. of at least three independent experiments. ${ }^{*} P<0.05$ compared with untreated cells. (c) Cells were preincubated with or without $5 \mu \mathrm{M} \mathrm{DPI}, 2.5 \mathrm{mM}$ Tempol or $10 \mathrm{mM}$ Tiron before treatment with simvastatin, cell viability was assessed by crystal violet staining and cell lysates were probed for caspase-3 cleavage. (d) Cells were preincubated with or without MVA, GGPP or FPP before exposure to simvastatin. (e) Cells were treated with NSC23766, transfected with Rac1N17, or transfected with siRNAs against RhoA, Rac1 or Cdc42 before simvastatin treatment. Intracellular superoxide level was determined using lucigenin chemiluminescence assay for both (d) and (e). Data are shown as mean \pm S.D. of at least three independent experiments. ${ }^{*} P<0.05$ compared with simvastatin treatment alone. Immunoblots are representative of at least two independent experiments 

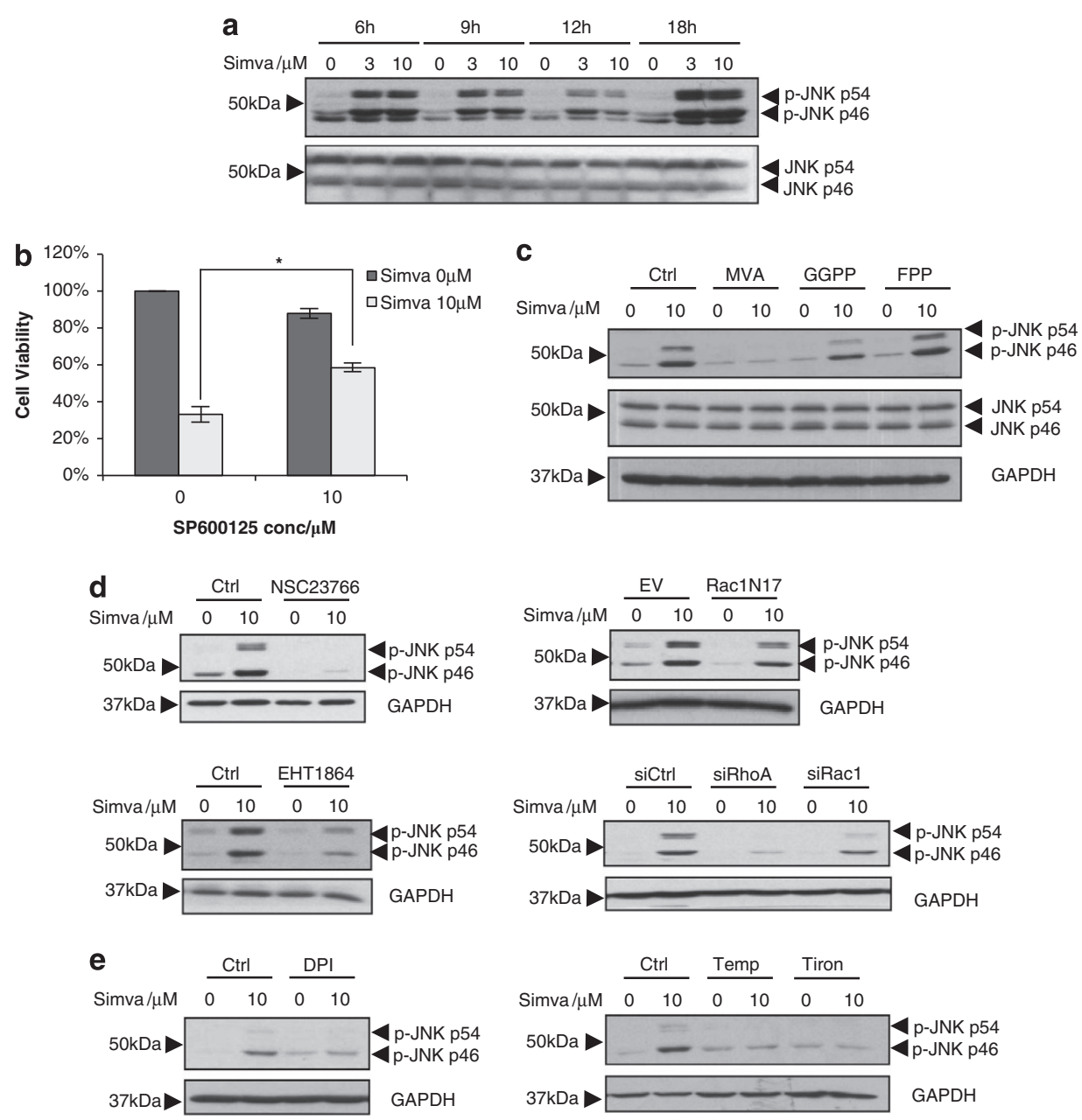

Figure 5 Simvastatin induces JNK activation downstream of Rho GTPases and superoxide production. (a) Cell lysates after simvastatin treatment was probed for phospho-JNK expression by western blotting. (b) Cells were pretreated with $10 \mu \mathrm{M} \mathrm{SP} 600125$ for $1 \mathrm{~h}$ before the addition of simvastatin for $48 \mathrm{~h}$. Cell viability was measured by crystal violet staining. Data are shown as mean \pm S.D. of at least three independent experiments. ${ }^{*} P<0.05$ compared with simvastatin treatment alone. (c) Cells were preincubated with MVA, GGPP or FPP followed by $10 \mu \mathrm{M}$ simvastatin for $24 \mathrm{~h}$. (d) Cells were pretreated with NSC23766, EHT1864, transfected with Rac1N17, siRhoA or siRac1 before treatment with simvastatin for $24 \mathrm{~h}$. (e) Cells were pretreated with DPI, Tempol or Tiron for $1 \mathrm{~h}$ before simvastatin treatment for $24 \mathrm{~h}$. In all (c-e), phospho-JNK level was assessed by western blotting. All immunoblots are representative of at least two independent experiments

cross talk existed between JNK activation and Rho GTPases-mediated superoxide production, following simvastatin exposure. Restoring protein geranylgeranylation via MVA or GGPP preincubation largely prevented simvastatininduced JNK phosphorylation (Figure 5c). Furthermore, pharmacological and genetic inhibition of RhoA or Rac1 activation, as well as preincubation with pharmacological scavengers of superoxide, also significantly abrogated JNK activation (Figures $5 \mathrm{~d}$ and e). These findings implicate JNK signaling as a downstream target of RhoA/Rac1 activation and superoxide production in simvastatin-induced apoptosis.

Simvastatin increases expression of pro-apoptotic Bim-EL in a JNK-dependent manner. Signaling by the JNK pathway has been linked to altered expression of several $\mathrm{Bcl}-2$ family members in other systems. ${ }^{30-32}$ Interestingly, we observed a sustained increase in the levels of the extra-long isoform of the pro-apoptotic Bcl-2 family protein Bim (Bim-EL) following simvastatin treatment
(Figure 6a), suggesting that this pro-apoptotic protein might be involved in simvastatin-induced colorectal cancer cell apoptosis. Indeed, siRNA-mediated silencing of Bim-EL provided significant protection from simvastatin-induced apoptosis (Figure 6b) and reduced simvastatin-mediated caspase-3 and PARP cleavage (Supplementary Figure S3), thus validating the role of Bim-EL as an apoptosis effector in our model system. In addition, pretreatment of HCT116 cells with the JNK inhibitor SP600125 markedly decreased simvastatin-mediated Bim-EL expression (Figure 6f). Similar effects were observed upon preincubation of cells with MVA, GGPP, inhibition of RhoA or Rac1 activation and scavenging of superoxide (Figures $6 \mathrm{c}-\mathrm{e}$ ).

Taken together, our data demonstrate that simvastatin elicits potent tumoricidal effects in HCT116 cells by activating the mitochondrial apoptotic pathway. By inhibiting protein geranylgeranylation, simvastatin paradoxically increases the active forms of RhoA and Rac1, which then leads to the activation of the downstream signaling cascade involving 
a

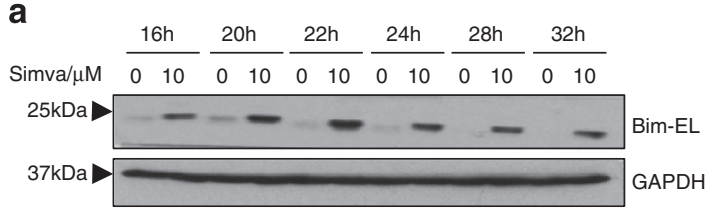

C

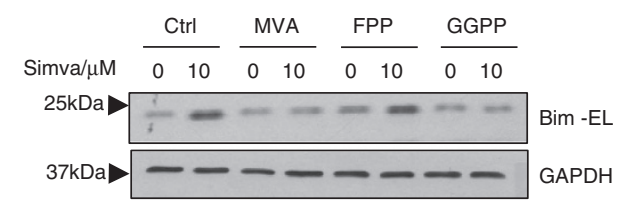

d
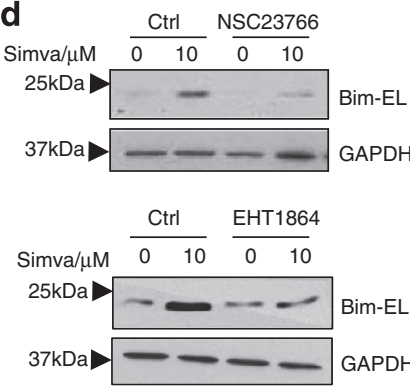

e

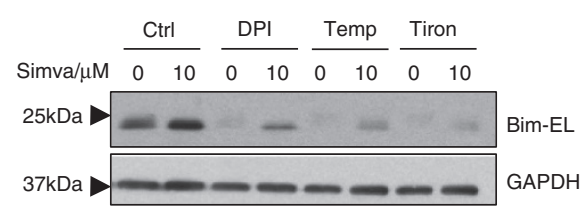

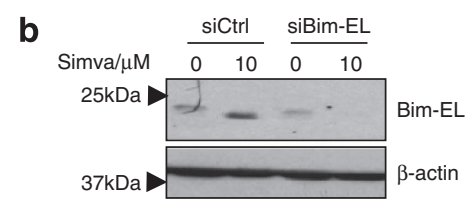
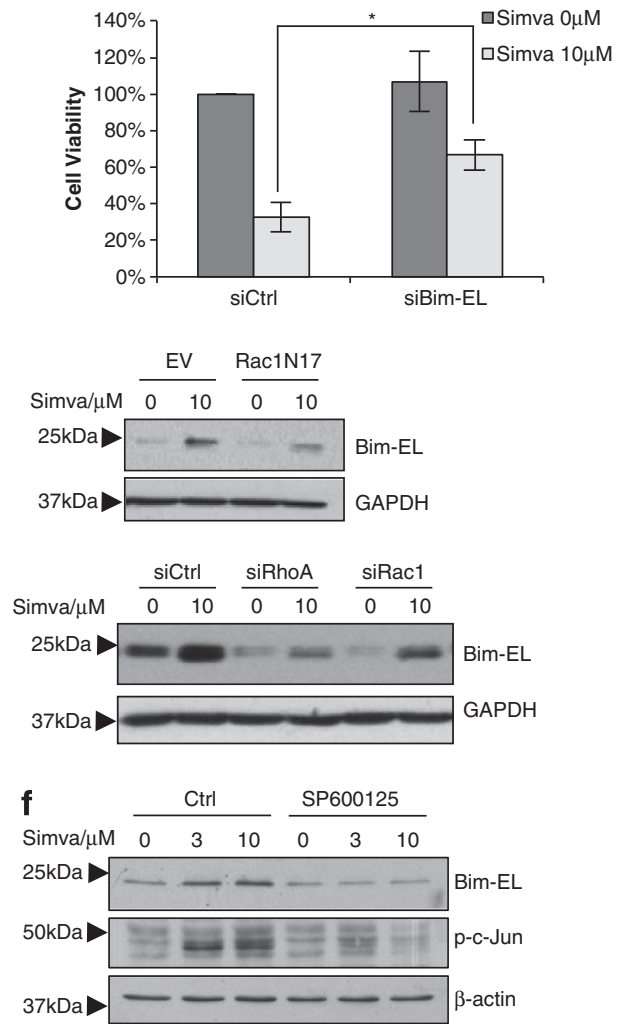

Figure 6 Simvastatin increases pro-apoptotic Bim-EL protein expression in a JNK dependent manner. (a) Cell lysates after simvastatin treatment was probed for Bim-EL expression by western blotting. (b) Cells were transfected with Bim siRNA (siBim-EL) to reduce Bim-EL protein expression before treatment with simvastatin for $48 \mathrm{~h}$. Cell viability was measured by crystal violet staining. Data are shown as mean \pm S.D. of at least three independent experiments. ${ }^{*} P<0.05$ compared with simvastatin treatment alone. (c) Cells were preincubated with MVA, GGPP or FPP followed by $10 \mu \mathrm{M}$ simvastatin for $24 \mathrm{~h}$. (d) Cells were pretreated with NSC23766, EHT1864, or transfected with Rac1N17, siRhoA or siRac1 before exposure to simvastatin for $24 \mathrm{~h}$. (e) Cells were pretreated with DPI, Tempol or Tiron for $1 \mathrm{~h}$ before simvastatin treatment for $24 \mathrm{~h}$. (f) Cells were pretreated with SP600125 for $1 \mathrm{~h}$ before simvastatin treatment for $24 \mathrm{~h}$. In all (c-f), Bim-EL expression was assessed by western blotting. All immunoblots are representative of at least two independent experiments

superoxide production, JNK activation and Bim-EL upregulation. The model is represented schematically in Figure 7. This phenomenon does not appear to be limited to this particular cell line, as studies using SHEP-1 neuroblastoma cells also implicated the multiple aforementioned players in mediating simvastatin's cytotoxic effects (Supplementary Figure S4). Overall, these findings not only provide compelling evidence for simvastatin's anticancer activities, but also suggest the importance of the identified molecular mechanism in other simvastatin-sensitive cancer cell types.

\section{Discussion}

Simvastatin-mediated apoptosis is dependent on protein geranylgeranylation. In the present study, we show that simvastatin induces potent cell death in colorectal cancer cell line HCT 116 by short-term cell viability assays and long-term colony formation assay. Further investigation revealed that the molecular events in simvastatin-induced cell death are consistent with classical apoptosis marked by proteolytic cleavage and activation of caspases. In addition, the almost complete protection of cells by pretreatment with pancaspase inhibitor zVAD-fmk confirms that simvastatin induces cell death via a caspase-dependent pathway. We also show that mitochondria are implicated in the apoptotic signaling elicited by simvastatin, as evidenced by the translocation of Bax to the mitochondria and release of cytochrome $\mathrm{c}$ into the cytosol. Further comparison between HCT116 wild type and its Bax knockout counterpart shows that Bax $-/$ - cells are much less sensitive to simvastatin treatment, confirming that Bax-mediated mitochondrial apoptotic pathway is the major mechanism responsible for simvastatin's apoptotic effects. This observation is consistent with several other reports, showing the importance of mitochondrial apoptotic pathway in breast tumor cells, ${ }^{33}$ lymphoblasts and myeloma cells ${ }^{34}$ upon exposure to statins. 


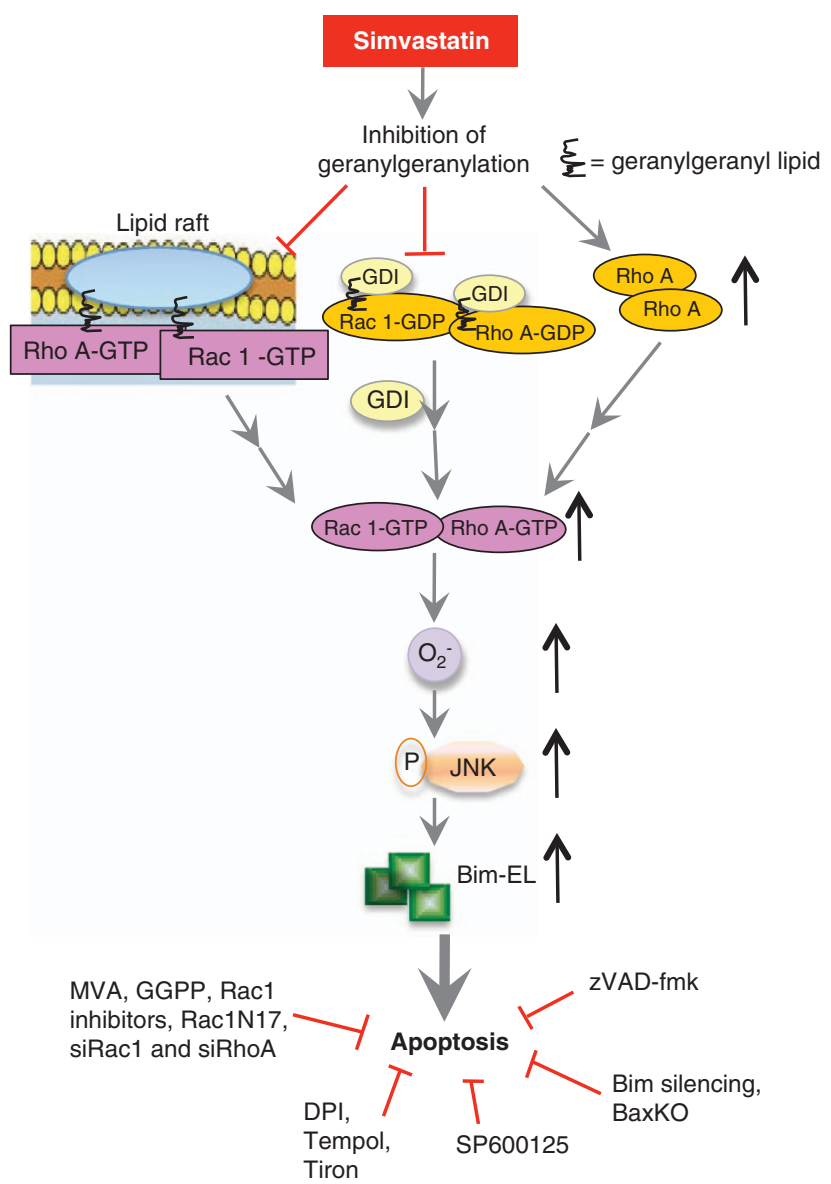

Figure 7 A schematic overview of the molecular mechanism in simvastatininduced apoptosis in colorectal cancer HCT116 cells

Several downstream metabolites in the MVA pathway have been suggested to be involved in establishing statins' antitumor effects, with most of the evidence pointing toward depletion of cellular GGPP. ${ }^{35-38}$ Our data also suggests that simvastatin induces apoptosis in HCT116 via GGPP depletion. In addition to HCT116 cells, we also observed that preincubation with GGPP rescues simvastatin's cytotoxicity in breast, lung and neuroblastoma cancer cells (Supplementary Figure S1B). One implication from these observations is that the impact from loss of protein geranylgeranylation on cell viability is more severe than loss of farnesylation, highlighting the critical involvement of one or more geranylgeranylated proteins, for example, Rho, Rac and Cdc42, in the growth and survival of transformed cells. In this regard, simvastatin treatment increased the levels of unprenylated RhoA, Rac1 and Cdc42 as expected, and correspondingly their cytosolic localization. Strikingly, however, simvastatin also promoted GTP loading of RhoA, Rac1 and Cdc42, and also increases in the total protein levels of RhoA and Cdc42. Importantly, these cytosolic GTP-loaded forms of RhoA and Rac1, but not apparently $\mathrm{Cdc} 42$, were functional to mediate cell death in simvastatin-treated HCT116 cells, as evidenced by the rescue from this cell death through pharmacological or genetic inhibition of RhoA or Rac1 function.
A mechanistic basis of the non-canonical activation of Rho proteins by simvastatin treatment came from the finding, confirming earlier reports, that inhibition of geranylgeranylation prevented Rho proteins from interacting with its negative regulator, RhoGDI. RhoGDIs are responsible for sequestering geranylgeranylated GDP-bound Rho proteins in a cytosolic complex and for preventing the guanine nucleotide exchange ${ }^{39}$ Hence, we propose that the decreased association between Rho proteins and their cytosolic inhibitor leads to the accumulation of GTP-bound Rho proteins, possibly owing to the spontaneous exchange of GTP for GDP or potentially involving activities of guanine nucleotide exchange factors. ${ }^{40}$ Growing evidence indicates that inhibition of prenylation is able to increase Rho proteins in their GTP-bound form regardless of their localization. The observation has not only been seen in the cancer cell lines used in the present study, but also in multiple cell types treated with statins, ${ }^{41}$ and in macrophages in which GGTase-I has been inactivated. ${ }^{42}$

In addition to the intriguing finding of Rho GTPase activation following simvastatin treatment, we observed elevated protein levels of RhoA and Cdc42 following such treatment that was reversed with GGPP preincubation. Previous studies have proposed that geranylgeranylated Rho proteins are more susceptible to proteasomal degradation; hence, inhibition of geranylgeranylation by statins might slow the degradation process and result in increased protein levels. ${ }^{43,44}$ However, we did not observe changes in protein stability of RhoA and Cdc42 in our model. Instead, de novo synthesis of mRNA and protein is more likely to be responsible for the increased protein expression, as pretreatment with transcription inhibitor actinomycin D (ActD) or protein synthesis inhibitor cycloheximide reduced protein levels of RhoA and Cdc42 induced by simvastatin (Supplementary Figure S5). More interestingly, we provide evidence that simvastatin-induced upregulation of Rho protein level is functionally relevant to the cell death signal, as cells treated with cycloheximide were much less sensitive to simvastatin treatment. Moreover, cycloheximide treatment reduced levels of the GTP-loaded RhoA and Rac1, the two Rho GTPases responsible for simvastatin-mediated apoptosis, suggesting that the newly synthesized unprenylated Rho proteins are those that get accumulated in the GTP-bound form.

Collectively, these studies have revealed that post-translational geranylgeranylation can impact Rho GTPases at both translational and post-translational levels, and that the resultant non-canonical activation of Rho GTPases produces species that are functional to meditate the apoptotic effects of simvastatin in cancer cells. Our results challenge the view that inhibiting geranylgeranylation is a means to block the activity of Rho-family proteins. On the contrary, inhibiting the process may stimulate both their expression and specific functions. Future investigations characterizing the status of Rho GTPases in statin-sensitive cancer cells should enhance our understanding of the molecular features required for the non-canonical regulation of Rho GTPases across different cell types.

Hierarchical involvement of superoxide, JNK, and Bim downstream of RhoA and Rac1 in simvastatin-induced cell death. To further explore the mechanism of how 
activation of RhoA and Rac1 mediate the cell death response to simvastatin, we identified superoxide production as an important downstream consequence of simvastatin treatment. Both Rac1 and RhoA are capable of activating the NADPH oxidase (NOX) complex that generates superoxide. Indeed, our data suggested that the NOX complex is a main source of superoxide production, as evidenced by the protective effect of the NOX inhibitor, DPI. ${ }^{45}$ Our preliminary findings showed that gene silencing of NOX2 significantly reduced superoxide level and protected cells from simvastatin-induced cellular insult (Supplementary Figure S6). These data indicate that the unprenylated yet activated RhoA and Rac1 can engage the NOX complex to generate superoxide in simvastatin-treated cells, which then leads to oxidative stress and cancer cell death. One important question that remains to be addressed is the site for the assembly of the functional NOX complex in simvastatintreated cancer cells, as this is unlikely to be the conventional location of the plasma membrane, as the unprenylated RhoA and Rac1 will not be found there.

The finding that superoxide generation is important in simvastatin-induced cell death raised the question as to whether JNK signaling was involved, as several studies have linked these two processes. Oxidative stress can modulate JNK activation, ${ }^{46,47}$ and JNK activation has been reported to be required for statin-mediated apoptosis in human breast cancer cells, ${ }^{48} \mathrm{C} 6$ glioma cells, ${ }^{49}$ salivary adenoid cystic cancer cells ${ }^{50}$ and ovarian cancer cells. ${ }^{51}$ Here, we were able to demonstrate a role for a Rhosuperoxide-JNK cascade in simvastatin-mediated apoptosis in HCT116 colorectal cells, indicating that this axis might also be active in other statin-sensitive cancer types. Furthermore, we identified the pro-apoptotic Bcl-2 family member Bim as a downstream target of the JNK pathway. This is consistent with the well-characterized role of JNKBim cascade in apoptosis in the nervous system upon NGF withdrawal. ${ }^{52-54}$ Previous studies have demonstrated that $\mathrm{Bim}$ is a unique $\mathrm{BH} 3$ protein that is able to directly induce the conformational changes of $\mathrm{Bax}$ and $\mathrm{Bak}$, or indirectly activates Bax and Bak by neutralizing the anti-apoptotic $\mathrm{Bcl}-2$ proteins, which precedes apoptosis. ${ }^{55}$ We propose that simvastatin-mediated increase in Bim-EL is likely to promote mitochondrial apoptosis by tilting the balance of pro- and anti-apoptotic Bcl-2 family proteins. Our findings demonstrate the importance of Bim-EL upregulation in statin-mediated cancer cell death, and reinforce the report of Jang et al. ${ }^{6}$ implicating Bim-EL upregulation in lovastatininduced glioblastoma cell death. Together with the signaling cascade we have established in simvastatin-treated HCT116 cells, our data in melanoma M14 cells further supports the notion that the JNK-Bim cascade may be a common mechanism activated by Rac1 signaling to mediate cell death in response to simvastatin treatment (Supplementary Figure S7).

Taken together, our data demonstrates the tremendous potential of simvastatin to induce cancer cell death. Further, the molecular players identified in these studies not only provide novel potential targets for therapeutic manipulation, but also lay the foundation to explore the role of statins as an adjuvant in combination therapies to treat cancer.

\section{Materials and Methods}

Cell lines and reagents. HCT116 WT $(\mathrm{p} 53+/-)$ and Bax $-/-$ colorectal carcinoma cells were generously provided by Dr. Bert Vogelstein (The Johns Hopkins University School of Medicine) and maintained in McCoy $5 \mathrm{~A}$ (Gibco Invitrogen, Carlsbad, CA, USA). Simvastatin, GGTI-298, FTI-277 and NSC23766 were purchased from Merck Millipore (Billerica, MA, USA). MVA, GGPP, FPP, SP600125, Tiron, Tempol, Triton X-114, DPI and cycloheximide were purchased from Sigma (St Louis, MO, USA). EHT1864 was purchased from Tocris Biosciences (Bristol, UK). Pan-caspase inhibitor ZVAD-fmk was purchased from Alexis Biochemicals (Lausanne, Switzerland).

Cell viability and tumor colony-forming assay. Cell viability following drug treatment was determined by both crystal violet staining and 3-(4,5dimethylthiazol-2-yl)-2,5 diphenyltetrazolium bromide (MTT) assay, as described previously. ${ }^{56,57}$ For colony-forming assay, 10000 cells per treatment were replated in a 6-well plate in complete tissue culture medium and grown for 7 days. The colonies formed were then stained with crystal violet (Sigma).

Transfection of plasmids and siRNAs. The Calcium Phosphate Mammalian Transfection Kit (Clonetech Laboratories, Palo Alto, CA, USA) was used for transfection of plasmids or siRNAs into HCT116 cells, according to the manufacturer's instructions. In all, $1 \mu \mathrm{g} / \mathrm{ml}$ of plRES1hyg vector (empty vector) and myc-tagged pIRESRacN17 plasmids (Rac1N17; generously provided by Dr. MarieVéronique Clément, Department of Biochemistry, Singapore) were used. For siRNAs, $35 \mathrm{nM}$ was used for siRNAs targeting RhoA and Cdc42, while $100 \mathrm{nM}$ was used for siBim-EL and siRac1. ON-TARGETplusSMARTpoolsiRNAs (a mixture of four siRNAs in a single reagent) targeting RhoA, Rac1, Cdc42 as well as siRNA-negative control were purchased from Dharmacon Technologies (Lafeyette, CO, USA). The single siBim sequence was purchased from Qiagen (Duesseldorf, Germany). Downstream procedures were carried out at least $30 \mathrm{~h}$ from the time of adding transfection reagents.

Antibodies used in western blotting. Primary antibodies specific for RhoA, Cdc42, RhoGDl $\alpha$, Bax, cytochrome c, voltage-dependent anion channel, $\beta$-actin and GAPDH were purchased from Santa Cruz Biotechnology (Santa Cruz, CA, USA). Bim, JNK, copper/zinc superoxide dismutase, PARP, myc-tag and caspase-3 were obtained from Cell Signaling Technology (Danvers, MA, USA), and Rac1 and phosphorylated-JNK were purchased from Merck Millipore. Flotilin was purchased from Abcam (Cambridge, UK).

Isolation of GTP-loaded RhoA, Rac1 and Cdc42 GTPases. The GTP-loaded form of RhoA, Rac1 and Cdc42 were pulled down with GST-Rhotekin beads (Cytoskeleton, Denver, CO, USA) or GST-PAK beads (Merck Millipore), respectively, according to the manufacturer's instructions.

Mitochondrial cytoplasmic fractionation. Mitochondrial and cytosolic fractions were obtained as described elsewhere. ${ }^{57}$ In this project, further purification was done to obtain cytosolic fractions free from contaminations from light membranes. After isolating the mitochondrial fractions, the supernatant was subjected to ultracentrifugation at $100000 \times g$ for $1 \mathrm{~h}$ at $4^{\circ} \mathrm{C}$, and the resultant supernatant was then subjected to western blot analysis.

Isolation of DRMs (lipid rafts) by sucrose gradient ultracentrifugation. Cells were lysed in HEPES buffer containing $1 \%$ Triton X-100, followed by homogenization for 20 strokes with a dounce homogenizer. The lysate was then subjected to 20 passes through a $27 \mathrm{G}$ syringe, followed by three times sonication ( $10 \mathrm{~s}$ pulses at $40 \mathrm{~V}$ ). The lysate was then mixed with an equal volume of $80 \%$ sucrose in HEPES buffer, followed by overlaying with $1.5 \mathrm{ml}$ of $30 \%$ sucrose and $1.5 \mathrm{ml}$ of $5 \%$ sucrose solutions. The sucrose gradient was centrifuged for $21 \mathrm{~h}$ at $4{ }^{\circ} \mathrm{C}$ at 32000 r.p.m., and eight $0.5 \mathrm{ml}$ fractions were harvested separately. Thirty microlitres from fraction number 2-6 were used for subsequent western blot analysis.

Triton X-114 phase separation. Cells were lysed in the lysis buffer (20 $\mathrm{mM}$ Tris, $150 \mathrm{mM} \mathrm{NaCl}, 1 \%$ Triton X-114) followed by centrifugation at $13000 \times g$ for $15 \mathrm{~min}$. The resultant mixture was incubated at $37^{\circ} \mathrm{C}$ for $10 \mathrm{~min}$ and two phases were separated by brief centrifugation (aqueous phase and detergent-rich pellet). The detergent-rich pellet was suspended in lysis buffer without Triton X-114. 
Determination of superoxide. Intracellular superoxide level was determined by a lucigenin-based chemiluminescence assay ${ }^{56}$ or a fluorescent probe Dihydroethidine (Invitrogen), as described previously. ${ }^{57}$

Statistical analysis. Numerical data were expressed as mean \pm S.D. Student's $t$-test was performed and the statistical significance was set at $P<0.05$.

\section{Conflict of Interest}

The authors declare no conflict of interest.

Acknowledgements. The work is supported by Grant: BMRC 08/1/21/19/565 from the Biomedical Research Council of Singapore.

1. Hwang KE, Na KS, Park DS, Choi KH, Kim BR, Shim H et al. Apoptotic induction by simvastatin in human lung cancer A549 cells via Akt signaling dependent down-regulation of survivin. Invest New Drugs 2011; 29: 945-952.

2. Demierre MF, Higgins PD, Gruber SB, Hawk E, Lippman SM. Statins and cance prevention. Nat Rev Cancer 2005; 5: 930-942.

3. Chan KK, Oza AM, Siu LL. The statins as anticancer agents. Clin Cancer Res 2003; 9 : 10-19.

4. Campbell MJ, Esserman LJ, Zhou Y, Shoemaker M, Lobo M, Borman E et al. Breast cancer growth prevention by statins. Cancer Res 2006; 66: 8707-8714

5. Fromigue $\mathrm{O}$, Hay E, Modrowski D, Bouvet $\mathrm{S}$, Jacquel A, Auberger $\mathrm{P}$ et al. RhoA GTPase inactivation by statins induces osteosarcoma cell apoptosis by inhibiting p42/p44-MAPKsBcl-2 signaling independently of BMP-2 and cell differentiation. Cell Death Differ 2006; 13 $1845-1856$

6. Jiang Z, Zheng X, Lytle RA, Higashikubo R, Rich KM. Lovastatin-induced up-regulation of the BH3-only protein, Bim, and cell death in glioblastoma cells. J Neurochem 2004; 89 168-178.

7. Ukomadu C, Dutta A. p21-dependent inhibition of colon cancer cell growth by mevastatin is independent of inhibition of G1 cyclin-dependent kinases. J Biol Chem 2003; 278 43586-43594.

8. Crick DC, Andres DA, Danesi R, Macchia M, Waechter CJ. Geranylgeraniol overcomes the block of cell proliferation by lovastatin in C6 glioma cells. J Neurochem 1998; 70 2397-2405

9. Jakobisiak M, Bruno S, Skierski JS, Darzynkiewicz Z. Cell cycle-specific effects of lovastatin. Proc Natl Acad Sci USA 1991; 88: 3628-3632.

10. Wu J, Wong WW, Khosravi F, Minden MD, Penn LZ. Blocking the Raf/MEK/ERK pathway sensitizes acute myelogenous leukemia cells to lovastatin-induced apoptosis. Cancer Res 2004; 64: 6461-6468.

11. Gniadecki R. Depletion of membrane cholesterol causes ligand-independent activation of Fas and apoptosis. Biochem Biophys Res Commun 2004; 320: 165-169.

12. Hentosh P, Yuh SH, Elson CE, Peffley DM. Sterol-independent regulation of 3-hydroxy-3 methylglutaryl coenzyme A reductase in tumor cells. Mol carcinogen 2001; 32: 154-166.

13. Jakobisiak M, Golab J. Potential antitumor effects of statins (Review). Int J Oncol 2003; 23: 1055-1069.

14. Wong WW, Dimitroulakos J, Minden MD, Penn LZ. HMG-CoA reductase inhibitors and the malignant cell: the statin family of drugs as triggers of tumor-specific apoptosis. Leukemia 2002; 16: 508-519.

15. Strandberg TE, Pyorala K, Cook TJ, Wilhelmsen L, Faergeman O, Thorgeirsson G et al. Mortality and incidence of cancer during 10-year follow-up of the Scandinavian Simvastatin Survival Study (4S). Lancet 2004; 364: 771-777.

16. Emberson JR, Kearney PM, Blackwell L, Newman C, Reith C, Bhala N et al. Lack of effect of lowering LDL cholesterol on cancer: meta-analysis of individual data from 175,000 people in 27 randomised trials of statin therapy. PloS One 2012; 7: e29849.

17. Brusca JS, Radolf JD. Isolation of integral membrane proteins by phase partitioning with Triton X-114. Methods Enzymol 1994; 228: 182-193.

18. Allal C, Favre G, Couderc B, Salicio S, Sixou S, Hamilton AD et al. RhoA prenylation is required for promotion of cell growth and transformation and cytoskeleton organization but not for induction of serum response element transcription. J Biol Chem 2000; 275 31001-31008.

19. Bordier C. Phase separation of integral membrane proteins in Triton X-114 solution. J Biol Chem 1981; 256: 1604-1607.

20. Anderson RG. The caveolae membrane system. Annu Rev Biochem 1998; 67: 199-225.

21. Brown DA, London E. Functions of lipid rafts in biological membranes. Annu Rev Cell Dev Biol 1998; 14: 111-136.

22. Simons K, lkonen E. Functional rafts in cell membranes. Nature 1997; 387: 569-572.

23. Waugh MG, Hsuan JJ. Preparation of membrane rafts. Methods Mol Biol 2009; 462 403-414.

24. Golub T, Wacha S, Caroni P. Spatial and temporal control of signaling through lipid rafts Curr Opin Neurobiol 2004; 14: 542-550.
25. Turner SJ, Zhuang S, Zhang T, Boss GR, Pilz RB. Effects of lovastatin on Rho isoform expression, activity, and association with guanine nucleotide dissociation inhibitors. Biochem Pharmacol 2008; 75: 405-413.

26. Kim JS, Diebold BA, Kim JI, Kim J, Lee JY, Park JB. Rho is involved in superoxide formation during phagocytosis of opsonized zymosans. J Biol Chem 2004; 279: 21589-21597.

27. Bokoch GM, Diebold BA. Current molecular models for NADPH oxidase regulation by Rac GTPase. Blood 2002; 100: 2692-2696

28. Bishop AL, Hall A. Rho GTPases and their effector proteins. Biochem J 2000; 348(Pt 2): 241-255.

29. Benhar M, Dalyot I, Engelberg D, Levitzki A. Enhanced ROS production in oncogenically transformed cells potentiates c-Jun $\mathrm{N}$-terminal kinase and p38 mitogen-activated protein kinase activation and sensitization to genotoxic stress. Mol Cell Biol 2001; 21 6913-6926.

30. Maundrell K, Antonsson B, Magnenat E, Camps M, Muda M, Chabert C et al. Bcl-2 undergoes phosphorylation by c-Jun N-terminal kinase/stress-activated protein kinases in the presence of the constitutively active GTP-binding protein Rac1. J Biol Chem 1997; 272 : 25238-25242

31. Milne DM, Campbell LE, Campbell DG, Meek DW. p53 is phosphorylated in vitro and in vivo by an ultraviolet radiation-induced protein kinase characteristic of the c-Jun kinase, JNK1. J Biol Chem 1995; 270: 5511-5518.

32. Whitfield J, Neame SJ, Paquet L, Bernard O, Ham J. Dominant-negative c-Jun promotes neuronal survival by reducing BIM expression and inhibiting mitochondrial cytochrome $c$ release. Neuron 2001; 29: 629-643.

33. Herrero-Martin G, Lopez-Rivas A. Statins activate a mitochondria-operated pathway of apoptosis in breast tumor cells by a mechanism regulated by ErbB2 and dependent on the prenylation of proteins. FEBS Letters 2008; 582: 2589-2594.

34. Cafforio P, Dammacco F, Gernone A, Silvestris F. Statins activate the mitochondrial pathway of apoptosis in human lymphoblasts and myeloma cells. Carcinogenesis 2005; 26: 883-891.

35. van de Donk NW, Kamphuis MM, van Kessel B, Lokhorst HM, Bloem AC. Inhibition of protein geranylgeranylation induces apoptosis in myeloma plasma cells by reducing $\mathrm{Mcl}-1$ protein levels. Blood 2003; 102: 3354-3362.

36. Zhong WB, Wang CY, Chang TC, Lee WS. Lovastatin induces apoptosis of anaplastic thyroid cancer cells via inhibition of protein geranylgeranylation and de novo protein synthesis. Endocrinology 2003; 144: 3852-3859.

37. Dimitroulakos J, Marhin WH, Tokunaga J, Irish J, Gullane P, Penn LZ et al. Microarray and biochemical analysis of lovastatin-induced apoptosis of squamous cell carcinomas. Neoplasia 2002; 4: 337-346.

38. Xia Z, Tan MM, Wong WW, Dimitroulakos J, Minden MD, Penn LZ. Blocking protein geranylgeranylation is essential for lovastatin-induced apoptosis of human acute myeloid leukemia cells. Leukemia 2001; 15: 1398-1407.

39. Dransart E, Olofsson B, Cherfils J. RhoGDIs revisited: novel roles in Rho regulation. Traffic 2005; 6: 957-966.

40. Orita S, Kaibuchi K, Kuroda S, Shimizu K, Nakanishi H, Takai Y. Comparison of kinetic properties between two mammalian ras p21 GDP/GTP exchange proteins, ras guanine nucleotide-releasing factor and smg GDP dissociation stimulation. J Biol Chem 1993; 268 : 25542-25546.

41. Cordle A, Koenigsknecht-Talboo J, Wilkinson B, Limpert A, Landreth G. Mechanisms of statin-mediated inhibition of small G-protein function. J Biol Chem 2005; 280. 34202-34209.

42. Khan OM, Ibrahim MX, Jonsson IM, Karlsson C, Liu M, Sjogren AK et al. Geranylgeranyltransferase type I (GGTase-I) deficiency hyperactivates macrophages and induces erosive arthritis in mice. J Clin Invest 2011; 121: 628-639.

43. Von Zee CL, Stubbs EB Jr. Geranylgeranylation facilitates proteasomal degradation of rho G-proteins in human trabecular meshwork cells. Invest Ophth Vis Sci 2011; 52 1676-1683.

44. Stamatakis K, Cernuda-Morollon E, Hernandez-Perera O, Perez-Sala D. Isoprenylation of $R h o B$ is necessary for its degradation: a novel determinant in the complex regulation of RhoB expression by the mevalonate pathway. J Biol Chem 2002; 277: 49389-49396.

45. O'Donnell BV, Tew DG, Jones OT, England PJ. Studies on the inhibitory mechanism of iodonium compounds with special reference to neutrophil NADPH oxidase. Biochem $J$ 1993; 290(Pt 1): 41-49.

46. Wong CH, Iskandar KB, Yadav SK, Hirpara JL, Loh T, Pervaiz S. Simultaneous induction of non-canonical autophagy and apoptosis in cancer cells by ROS-dependent ERK and JNK activation. PloS One 2010; 5: e9996.

47. Shenoy K, Wu Y, Pervaiz S. LY303511 enhances TRAlL sensitivity of SHEP-1 neuroblastoma cells via hydrogen peroxide-mediated mitogen-activated protein kinase activation and up-regulation of death receptors. Cancer Res 2009; 69: 1941-1950.

48. Koyuturk M, Ersoz M, Altiok N. Simvastatin induces apoptosis in human breast cancer cells: p53 and estrogen receptor independent pathway requiring signalling through JNK. Cancer Lett 2007; 250: 220-228.

49. Koyuturk M, Ersoz M, Altiok N. Simvastatin induces proliferation inhibition and apoptosis in C6 glioma cells via c-jun N-terminal kinase. Neurosci Lett 2004; 370: 212-217. 
50. Zhang S, Wang XL, Gan YH, Li SL. Activation of c-Jun N-terminal kinase is required for mevastatin-induced apoptosis of salivary adenoid cystic carcinoma cells. Anticancer Drug 2010; 21: 678-686.

51. Liu H, Liang SL, Kumar S, Weyman CM, Liu W, Zhou A. Statins induce apoptosis in ovarian cancer cells through activation of JNK and enhancement of Bim expression. Cancer Chemother Pharmacol 2009; 63: 997-1005.

52. Becker EB, Howell J, Kodama Y, Barker PA, Bonni A. Characterization of the c-Jun $\mathrm{N}$-terminal kinase-BimEL signaling pathway in neuronal apoptosis. J Neurosci 2004; 24 : 8762-8770.

53. Harris $\mathrm{CA}$, Johnson EM Jr. BH3-only Bcl-2 family members are coordinately regulated by the JNK pathway and require Bax to induce apoptosis in neurons. J Biol Chem 2001; 276: 37754-37760.

54. Putcha GV, Moulder KL, Golden JP, Bouillet P, Adams JA, Strasser A et al. Induction of $\mathrm{BIM}$, a proapoptotic BH3-only BCL-2 family member, is critical for neuronal apoptosis. Neuron 2001; 29: 615-628.
55. Czabotar PE, Colman PM, Huang DC. Bax activation by Bim? Cell Death Differ 2009; 16: 1187-1191.

56. Clement MV, Ponton A, Pervaiz S. Apoptosis induced by hydrogen peroxide is mediated by decreased superoxide anion concentration and reduction of intracellular milieu. FEBS Lett 1998; 440: 13-18.

57. Chen ZX, Pervaiz S. Bcl-2 induces pro-oxidant state by engaging mitochondrial respiration in tumor cells. Cell Death Differ 2007; 14: 1617-1627.

(c) (i) $\odot$ Cell Death and Disease is an open-access journal published by Nature Publishing Group. This work is licensed under a Creative Commons Attribution-NonCommercialNoDerivs 3.0 Unported License. To view a copy of this license, visit http://creativecommons.org/licenses/by-nc-nd/3.0/

Supplementary Information accompanies this paper on Cell Death and Disease website (http://www.nature.com/cddis) 